\title{
Automatisch gut?
}

\section{Liebe Leserin, lieber Leser,}

das automatisierte Fahren bewegt unsere Branche schon seit einiger Zeit intensiv. Sämtliche Entwicklungsdienstleister, Zulieferer und OEMs investieren Milliardensummen und arbeiten mit Hochdruck an neuen Systemen, die immer höhere Automatisierungsgrade ermöglichen. Aus gutem Grund - schließlich ist die Zukunftsvision verheißungsvoll. Auch wenn die sogenannte Vision Zero auf lange Sicht unrealistisch erscheint, wird die zunehmende Automatisierung zu einem dramatischen Anstieg der Verkehrssicherheit führen. Zudem wird sie völlig neue Mobilitätskonzepte ermöglichen, die die rasant wachsenden urbanen Zentren vor dem Verkehrskollaps bewahren und ländliche Gebiete wieder attraktiver machen könnten.

Nicht zuletzt deshalb hat unsere Redaktion nach der Premierenausgabe im vergangenen Jahr wieder ein ATZextra zusammengestellt, das sich der Thematik aus zahlreichen Blickwinkeln widmet. So zeigen wir in dieser Ausgabe unter anderem, wie künftige Mobilitätslösungen für Großstädte aussehen könnten, wie Fahrstrategiefunktionen auf Basis neuer Algorithmen entwickelt oder wie die Systeme im realen Straßenbetrieb getestet werden.

Aber auch außerhalb von Fachpublikationen erreichte das Thema in den letzten Wochen hohe mediale Aufmerksamkeit. Zunächst durch den tödlichen Unfall mit dem Uber-Testfahrzeug, kurz danach krachte in den USA ein Tesla mit aktiviertem Autopiloten ausgerechnet in einen Polizeiwagen. Flankiert wurden die beiden Unfallereignisse von Dorothee Bär, die etwas zu optimistisch über Flugtaxis fabulierte, was ihr bei scherzigen Zeitgenossen auf Twitter Hohn und Spott einbrachte. Die Reaktionen auf diese Unfallereignisse und die Staatsministerin für Digitales zeigen jedoch, dass beim automatisierten Fahren nicht alles auch automatisch gut wird. Zwar besitzen die deutschen OEMs in diesem Bereich weiterhin die meisten Patente weltweit doch das Thema ist komplexer und hat mehr als nur die technische Dimension. Da ist zum einen die Ebene der Akzeptanz und des Vertrauens. Hersteller und Entwickler sind daher gut beraten, nicht zu überpacen. Sie sollten auf eine schrittweise, dafür aber sichere Einführung der Systeme setzen. Eine zweite Ebene ist die Politik. Hier muss ebenfalls noch ein breites Feld beackert werden. Neben der Gesetzgebung betrifft das insbesondere den flächendeckenden Ausbau der Mobilfunknetze und Teststrecken also Grundvoraussetzungen für automatisierte Fahrfunktionen. Gerade in diesem Feld läuft Deutschland gegenüber den anderen Leitmärkten wie den USA oder China Gefahr, deutlich ins Hintertreffen zu geraten.

Ich wünsche Ihnen eine angenehme und interessante Lektüre.

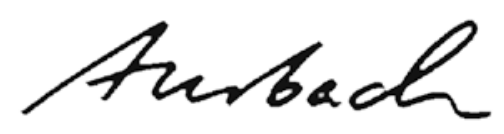

Benjamin Auerbach,

Editorial Manager Corporate Solutions

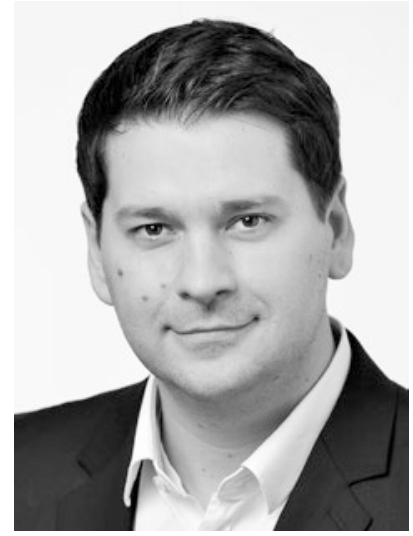

Freihändig fahren?

\section{Alles eine Frage der Methode.}

Fahrerassistenzsysteme verändern das Auto. Stark vernetzt und zunehmend offen können die sicherheitskritischen Helfer jedoch auch Etabliertes ins Wanken bringen. Für die richtige Balance vereinen wir Systems Engineering, Safety und Security sowie intelligente Testmethoden zu einem funktionsorientierten Gesamtkonzept. Und damit Sie noch mehr Wege erkunden können, sind unsere Lösungen skalier- und wiederverwendbar.

ITK Engineering GmbH - Ihr methodischer Partner für mehr Fahrfreiheit.

www.itk-engineering.de

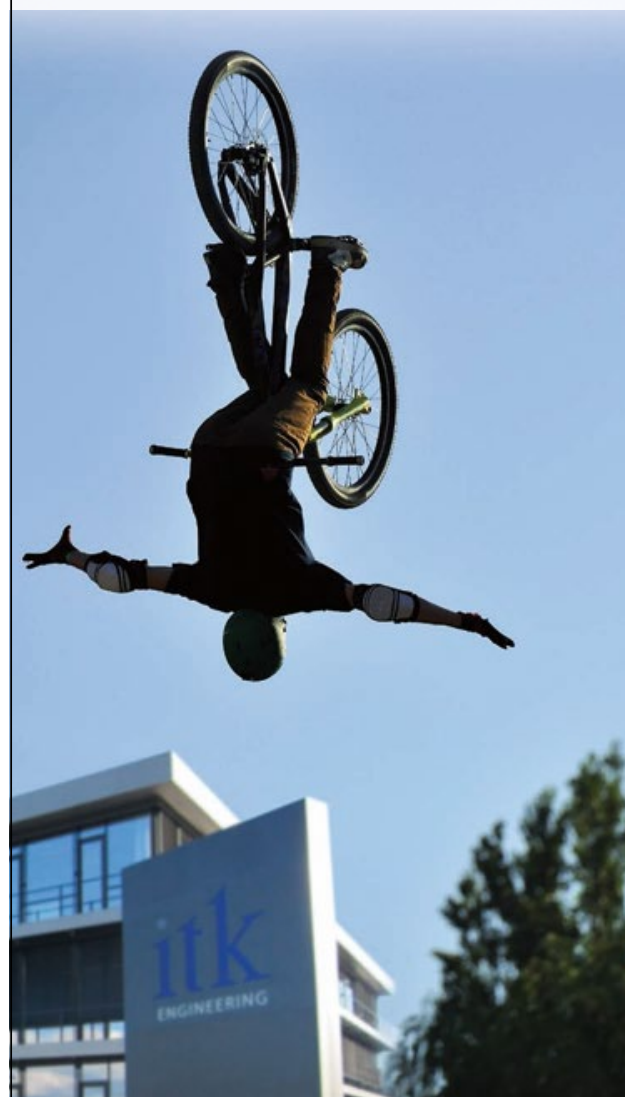

